\title{
Contribución al estudio de aditivos orgánicos en el proceso de fermentación del grano de café
}

\section{Contribution to the study of organic additives in the fermentation process of coffee bean grain}

\section{Milton Cesar Ararat Orozco ${ }^{1}$}

PhD Ciencias Agropecuarias

Escuela de Ciencias Agrícolas, Pecuarias y del Medio Ambiente -ECAPMA. Universidad Nacional Abierta y a Distancia -UNAD

https://orcid.org/0000-0003-2482-1834

milton.ararat@unad.edu.co

\section{Luisa Fernanda Trujillo ${ }^{2}$}

Agrónoma

Escuela de Ciencias Agrícolas, Pecuarias y del Medio Ambiente -ECAPMA. Universidad Nacional Abierta y a Distancia -UNAD

lufetrujillo@hotmail.com

\section{RESUMEN}

En el proceso de fermentación del grano de café al igual que la de otros alimentos (por ejemplo, en lácteos como el yogurt), se realiza gracias al trabajo de los microorganismos y moléculas orgánicas esenciales para mejorar la composición química y organoléptica de la bebida. Teniendo en cuenta las propiedades que los consumidores buscan en la bebida del café, se seleccionó la miel de panela (T1), infusión de limoncillo (T2) y microorganismos eficientes (T3) como aditivos durante todo el proceso de fermentación, por ser la etapa donde el grano sufre alteraciones naturales gracias a la acción de las levaduras y bacterias presentes en el mucilago que degradan los azúcares, proteínas, ácidos y lípidos, convirtiéndolos en alcoholes, ácidos y ésteres, dichas sustancias son los que cambian el olor, el pH del mucilago y los granos de café. Los resultados indicaron que los tratamientos T1 y T3 alcanzaron los mayores promedios de temperaturas y grados BRIX. Ninguno de los tratamientos afectó negativamente la apariencia del grano ni el sabor de la bebida pues los resultados del laboratorio de calidades fueron satisfactorios, logrando calificaciones superiores a 83,5 a excepción del testigo.

DOI: https://doi.org/10.22490/ECAPMA.2949 
Palabras clave: Fermentación; calidad de café; productos orgánicos.

\section{ABSTRACT}

In the process of fermentation of coffee beans as well as other foods (for example in dairy products such as yogurt), it is done thanks to the work of microorganisms and organic molecules essential to improve the chemical and organoleptic composition of the beverage. Taking into account the properties consumers are looking for in the coffee drink, panela honey (T1), infusion of lemongrass (T2) and efficient microorganisms (T3) were selected as additives during the whole fermentation process, as the stage where the grain undergoes natural alterations thanks to the action of the yeasts and bacteria present in the mucilage that degrade the sugars, proteins, acids and lipids, converting them into alcohols, acids and esters, said substances are those that change the smell, the $\mathrm{pH}$ of the mucilage and coffee beans. The results indicated that the T1 and T3 treatments reached the highest average temperatures and BRIX degrees. None of the treatments negatively affected the appearance of the grain or the flavor of the drink, as the results of the laboratory of qualities were satisfactory, achieving grades higher than 83.5 with the exception of the control.

Keywords: Fermentation; coffee quality; organic products. 


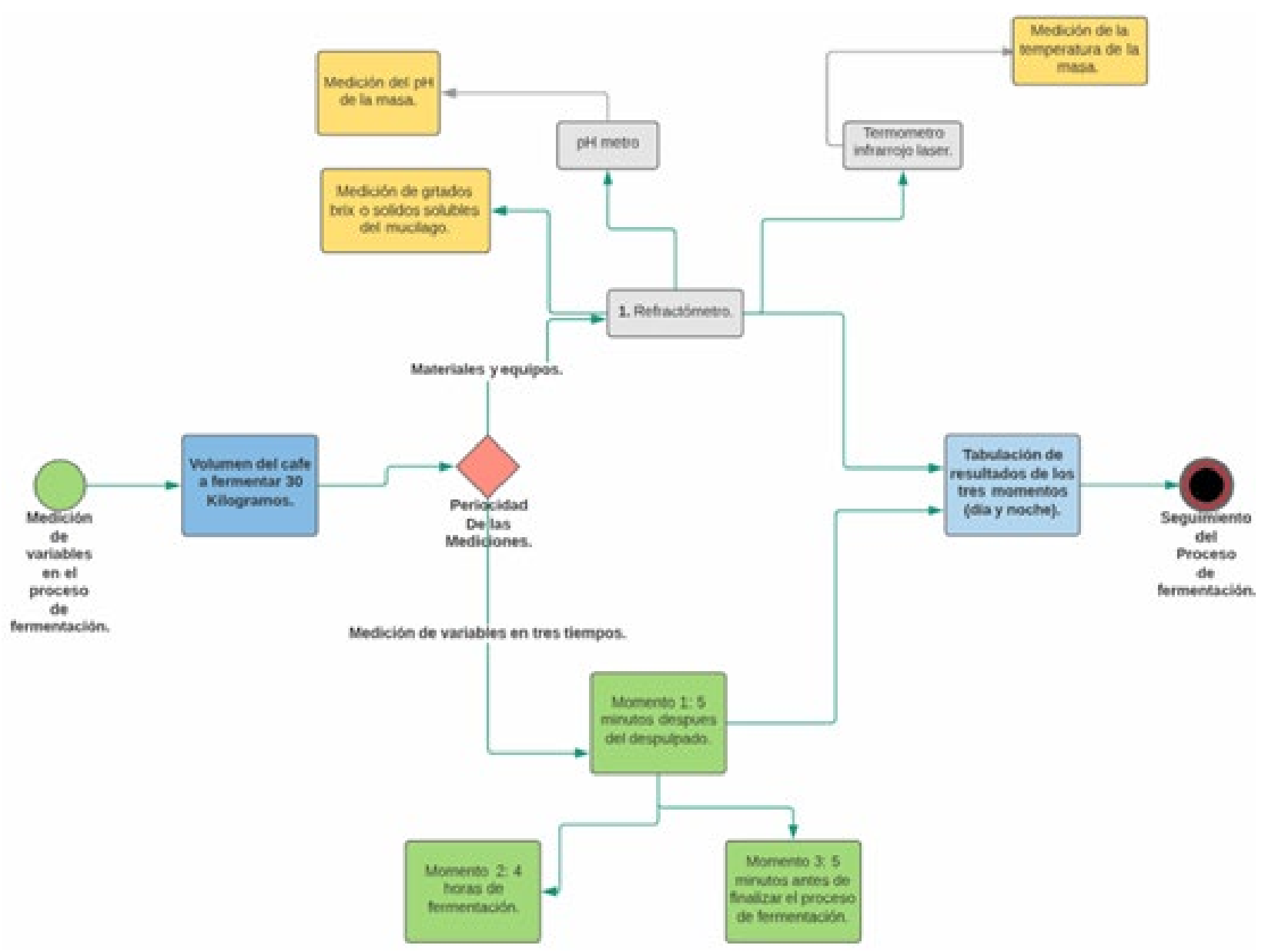

Resumen gráfico. Diagrama representativo de la evaluación de aditivos orgánicos en el proceso de fermentación del grano del grano de café

\section{INTRODUCCIÓN}

Actualmente, existen tendencias marcadas frente a la producción de café, entre las que se destacan la valoración de impactos ecológicos (Gamboa, 2015), los servicios ecosistémicos (Corredor, Fonseca \& Páez, 2012), la sustentabilidad agroambiental (Giraldo \& Valencia, 2010), el turismo rural comunitario (Vinasco, 2017), la fauna y la flora asociadas (Bonilla \& Caetano, 2013), las posibilidades de desarrollo rural (Matos de Oliveira, 2014; Duarte y Arana-Gutiérrez, 2016), el cambio climático (Mendoza, Cano \& Rojas, 2015), los derechos de los consumidores (Zapata \& Llano, 2014). 
Técnicamente se recomienda despulpar el grano de café seguidamente se haya recolectado, esta actividad consiste en pasar el fruto por una máquina (despulpadora), donde por fricción se descarta la cereza del grano, el cual pasa a los tanques de fermentación en donde persistirá por un lapso de tiempo que va de 12 a 18 horas dependiendo de factores ambientales, variedad del café, volumen del café a transformarse, instalaciones, maquinaria y grado de madurez entre otros, durante este proceso se logra el desprendimiento del mucílago o baba del grano, gracias a la acción de los microorganismos, levaduras y las bacterias del mucilago, los cuales mediante sus enzimas naturales oxidan parcialmente los azucares logrando el proceso de fermentación, donde se evidencia el cambio de color de la masa, el olor y el volumen (CENICAFÉ, 1996). La fermentación es un proceso catabólico de oxidación de sustancias orgánicas para producir otros compuestos orgánicos y energía, este proceso es realizado por levaduras, microorganismos y bacterias en ausencia o presencia de oxígeno. (Puerta, 2012).

En la fermentación ocurren diversos procesos en donde las levaduras y bacterias del mucilago, mediante sus enzimas oxidan los azucares y producen energía (etanol, ácido láctico, ácido acético, dióxido de carbono. Además de obtener otros alcoholes como butanol, propanol y otras sustancias olorosas, degradándose los lípidos del mucilago, con lo cual cambia, el olor, densidad, $\mathrm{pH}$, temperatura y composición química y microbiana de la masa (Puerta, 2012). El proceso de evaluación de aditivos orgánicos en la fermentación del mucilago de café contribuye a la investigación, aplicación y evaluación de programas de capacitación; De acuerdo con Vera \& Vera (2016), estas actividades logran establecer logros enfocados a las competencias administrativas de los extensionistas de este sector.

\section{MATERIALES Y MÉTODOS}

La evaluación de los procesos de fermentación controlada con aditivos orgánicos y las variables de tiempo se realizaron en las fincas La Palma y El Rincón de David, ubicadas en las veredas Sevilla y El Zarzal respectivamente del municipio "El Tambo" departamento del Cauca, ubicadas a alturas de 1687 y 1700 msnm en el mismo orden, con temperaturas promedio anual de $21^{\circ} \mathrm{C}$. Para cada uno de los tratamientos se utilizaron 50 Kilogramos de café cereza recolectados en óptimo grado 
de madurez, una vez despulpado se depositaron sin cascara (en babaza) en tanques añadiendo el aditivo orgánico durante 14 y 16 horas de fermentación del café en mucilago; La descripción de los tratamientos ( $T$ ) se presenta de la siguiente manera:

T1: Fermentado + aplicación de Miel de panela durante 16 horas.

T2: Fermentado + aplicación de Té de limoncillo durante 16 horas.

T3: Fermentado + aplicación de microorganismos eficientes durante 14 horas.

T Testigo: Fermentado SIN la aplicación de aditivos orgánicos durante 16 horas.

Cada tratamiento presento 3 repeticiones.

En el proceso de fermentación, se analizaron variables con los siguientes equipos: refractómetro óptico para sólidos solubles en una disolución líquida, termo-higrómetro para humedad relativa (\%HR) y temperaturas (TEM) Máxima y mínima y el medidor de $\mathrm{pH}$ y grados Brix a la masa de café y al mucílago por separado; durante la etapa de secado se controló permanentemente la temperatura hasta la humedad del $10-11,5 \%$. Para percibir, identificar apreciar algunas propiedades características del café, se determinaron los efectos en el análisis sensorial teniendo en cuenta en cuenta el nivel óptimo de humedad de los tratamientos; posteriormente se llevaron al laboratorio de calidades para realizar la catación garantizando objetividad en la valoración de cada proceso.

La valoración de los principios de catación se realiza de acuerdo a la norma SCA (2004) con los siguientes ítems: Fragancia/ aroma, sabor, sabor residual, acidez, cuerpo, uniformidad, balance, taza limpia y dulzor que generan el correspondiente puntaje (Specialty Coffee association of América (SCAA, 2015).

Tabla 1. Descripción de los tratamientos de fermentación del gran de café

\begin{tabular}{c|l|c|c|c|c}
\hline Tratamiento & \multicolumn{1}{|c|}{ Aditivo biológico y Proceso } & $\begin{array}{c}\text { Cantidad } \\
\text { de aditivo }\end{array}$ & $\begin{array}{c}\text { Cantidad } \\
\text { de café } \\
\text { cereza }\end{array}$ & $\begin{array}{c}\text { Cantidad } \\
\text { de café } \\
\text { en baba }\end{array}$ & $\begin{array}{c}\text { Tiempo de } \\
\text { fermentació } \\
\text { n en horas. }\end{array}$ \\
\hline T Testigo & $\begin{array}{l}\text { Fermentación natural, Tratamiento } \\
\text { testigo }\end{array}$ & Sin aditivo & $50 \mathrm{~kg}$ & $30 \mathrm{Kg}$ & 16 \\
\hline & $\begin{array}{l}\text { Se añaden } 600 \text { ml. de miel de panela al } \\
\text { inicio de la fermentación de cada }\end{array}$ & $0,6 \mathrm{Lts}$. & & & \\
\hline
\end{tabular}




\begin{tabular}{c|l|c|c|c|c}
\hline T1 & periodo. & $(2 \%)$ & $50 \mathrm{~kg}$ & $30 \mathrm{Kg}$ & 16 \\
\hline $\mathrm{T} 2$ & $\begin{array}{l}\text { Se añaden 600 ml. De infusión de } \\
\text { limoncillo al inicio de la fermentación de } \\
\text { cada periodo. }\end{array}$ & $\begin{array}{c}0,6 \mathrm{Lts} . \\
(2 \%)\end{array}$ & $50 \mathrm{~kg}$ & $30 \mathrm{Kg}$ & 16 \\
\hline $\mathrm{T} 3$ & $\begin{array}{l}\text { Se añaden 600 ml. Microrganismos } \\
\text { Eficientes (ME) al inicio de la } \\
\text { fermentación de cada periodo. }\end{array}$ & $\begin{array}{l}300 \mathrm{~g} \\
(1 \%)\end{array}$ & $50 \mathrm{~kg}$ & $30 \mathrm{Kg}$ & 14 \\
\hline
\end{tabular}

Fuente: Autores (2018)

Las muestras fueron llevadas al laboratorio de calidades de Federación Campesina del Cauca, donde se realizaron las pruebas físicas y sensoriales de cada tratamiento. Se mezclaron 100 gramos de cada uno de los tratamientos, incluyendo el testigo, con el objetivo de evaluar la consistencia en taza.

\section{RESULTADOS Y DISCUSIÓN}

En la figura 1 se muestran los resultados del procedimiento de monitoreo de los tiempos de fermentación, donde el tratamiento con Microorganismos Eficientes (T3) presentó el menor tiempo con reportes de 14 horas, mientras que los tratamientos con la miel de panela (T1), infusión de limoncillo (T2) y el testigo (TT) el tiempo fue de 16 horas. Una vez alcanzada esta etapa de fermentación se lavó el grano con agua limpia de 3 a 4 veces con el fin de retirar el mucílago para luego llevar el grano a la etapa de secado.

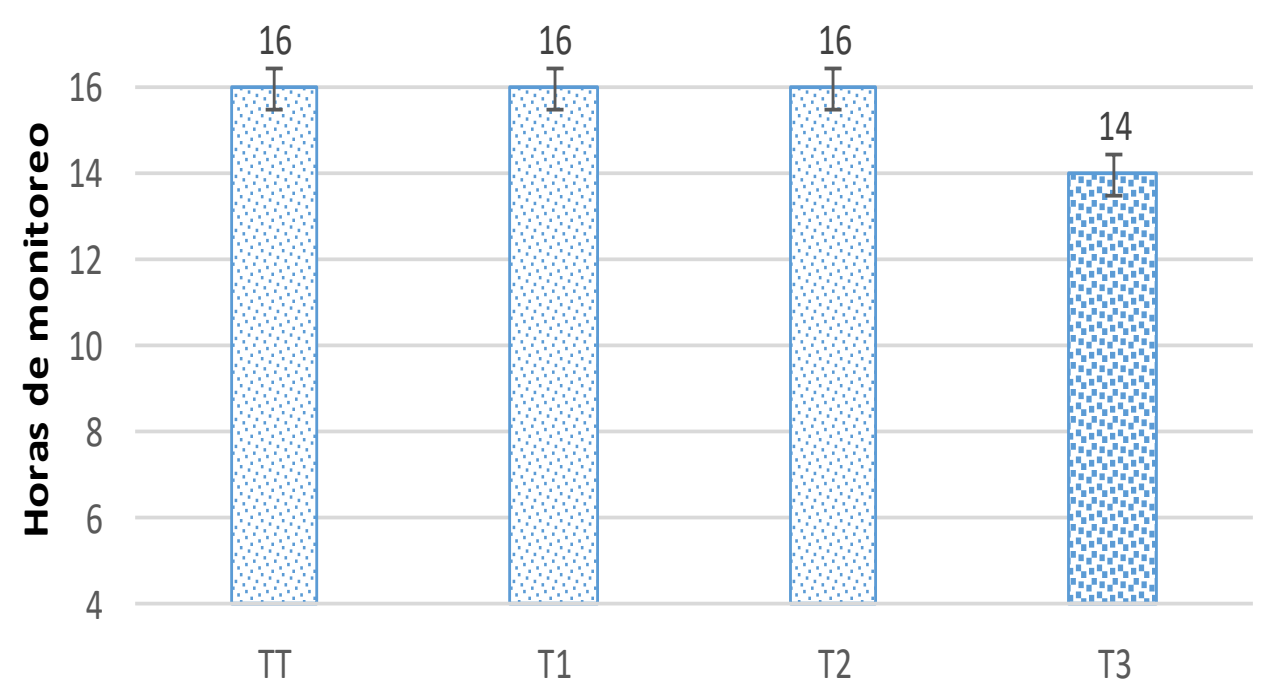


Figura 1. Tiempos en la fermentación de grano cereza de café con la aplicación de aditivos orgánicos.

Fuente: Autores (2018)

En la variable de respuesta "temperatura de la masa" monitoreada durante la noche (Figura 2), se evidenció que los tratamientos T1 y T3 alcanzaron los mayores promedios; Comparando con la figura 3, esta variable tuvo mayor valor en el monitoreo nocturno que el diurno para los cuatro procesos o tratamientos siendo el T1 en la temporalidad quien marca la mayor diferencia de temperatura con $1,5{ }^{\circ} \mathrm{C}$. Una tendencia similar se registró en la variable grados ${ }^{0}$ BRIX tanto en el día como en la noche, siendo el T1 el de mayor valor, probablemente por asociarse a la concentración de azúcares en la Miel de Panela.

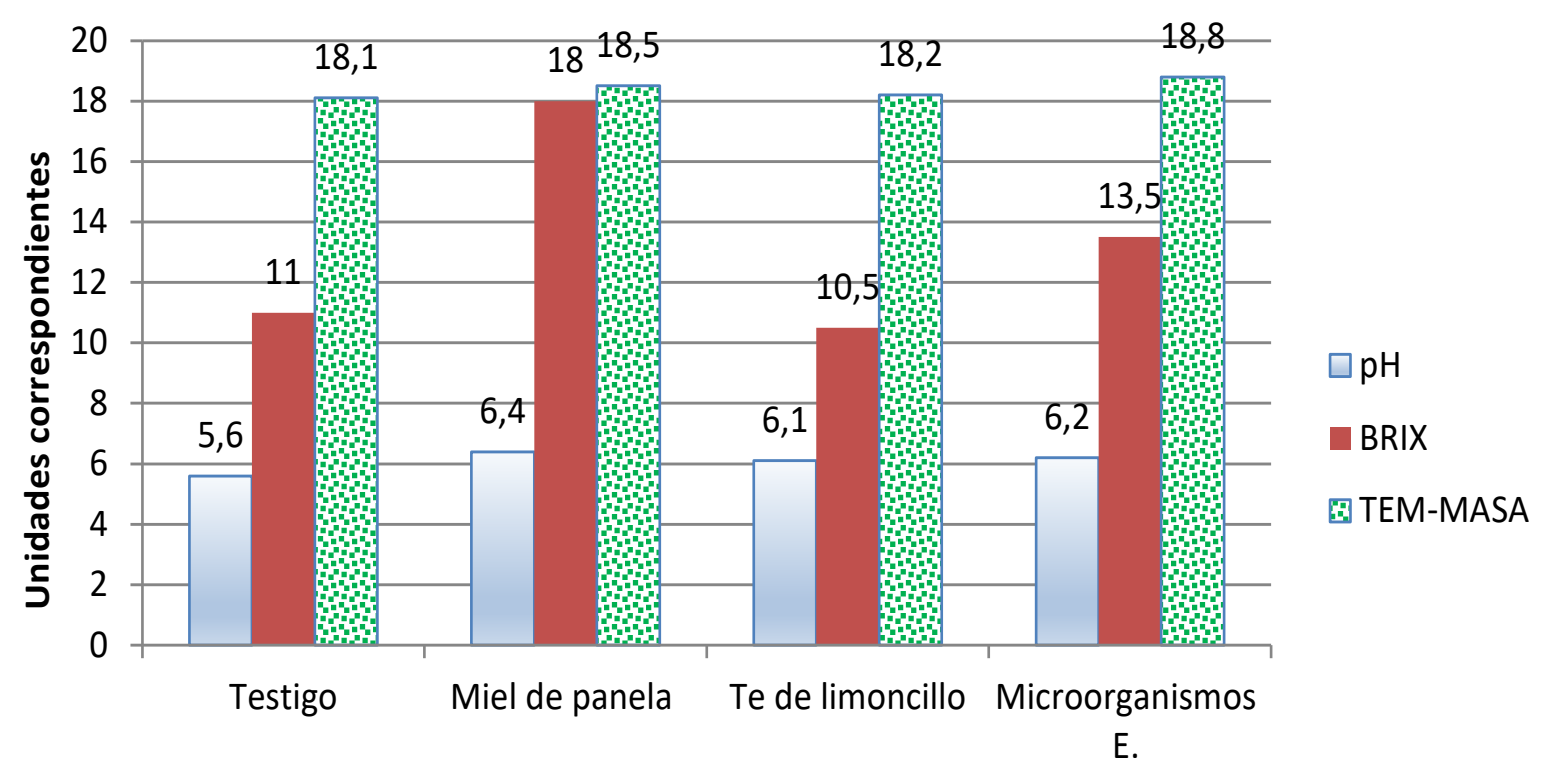

Figura 2. Mediciones del $\mathrm{pH},{ }^{0} \mathrm{BRIX}$ y temperatura de la masa (TEM-MASA). (Valores registrados durante la noche). Fuente: Autores (2018)

En la fase del monitoreo diurno el T1 presentó el valor del pH más ácido 4,8 (Figura 3), sin embargo, este parámetro se bajó para todos los tratamientos en comparación con el monitoreo nocturno. 


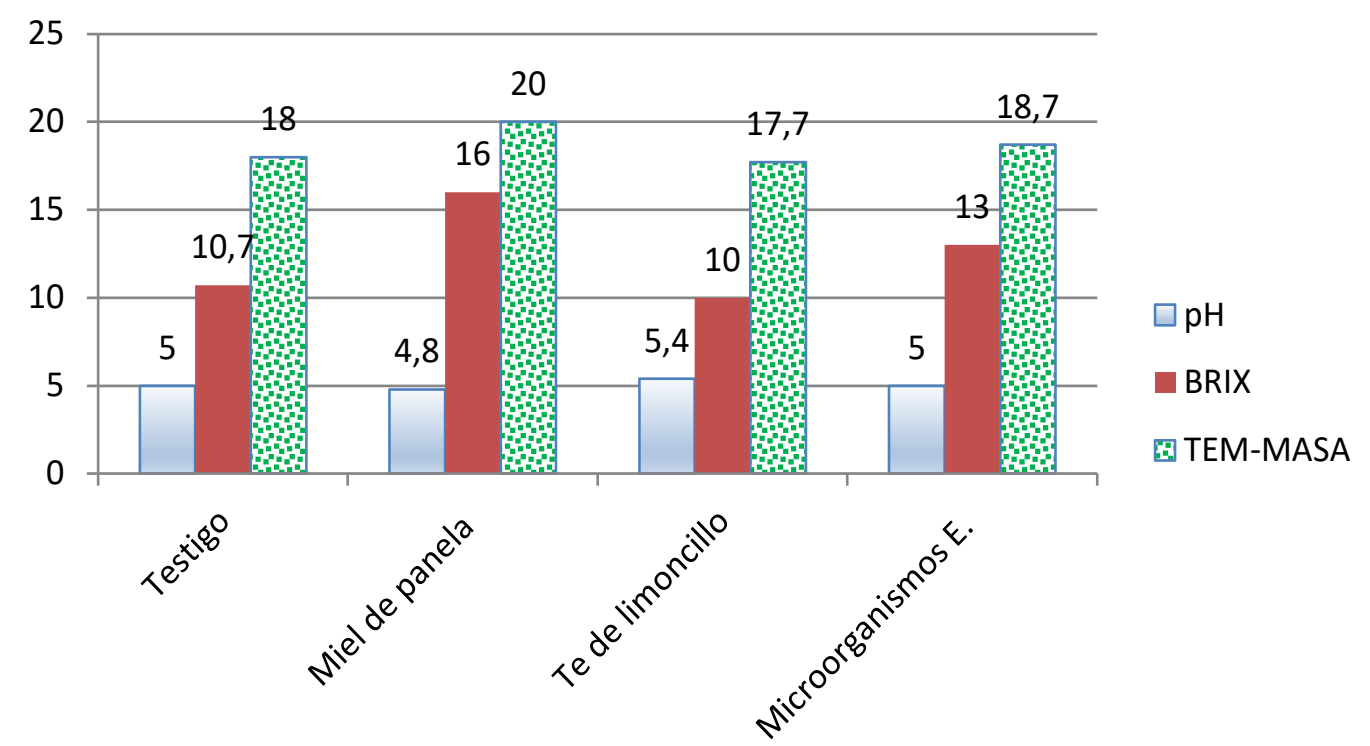

Figura 3. Mediciones del $\mathrm{pH}$, OBRIX y temperatura de la masa (TEM-MASA). (Valores registrados durante el día). Fuente: Autores (2018)

Los tres aditivos orgánicos utilizados durante la fermentación del café (miel de panela, té de limoncillo y microorganismos eficientes), no afectaron negativamente la apariencia del grano ni el sabor de la bebida pues los resultados del laboratorio de calidades fueron satisfactorios, logrando calificaciones superiores a 84 puntos con los cuales se podría participar en mercados de cafés especiales, sin embargo, los testigos no superaron los 83,5 puntos en taza (Figura 4 ).

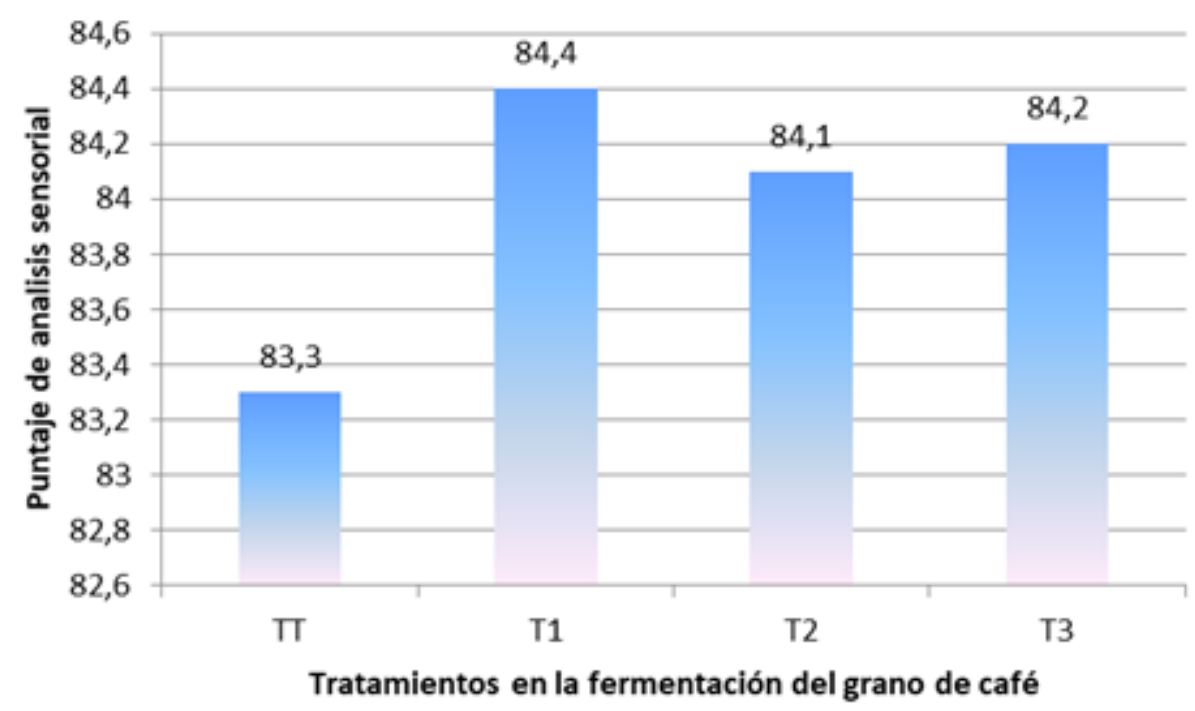


Figura 4. Valores promedios en el análisis sensorial de calidad de la bebida de café.

Fuente: Autores (2018)

Estos resultados permiten relacionar lo que sustenta Martin (2018), argumentando que la investigación en fitoquímica debe estar encaminada a identificar, aislar y caracterizar compuestos sintetizados por las plantas, siendo el estudio de las rutas biosintéticas, procedimientos e analíticos y métodos de separación robustos, las áreas de explicación profunda sobre los mecanismos de acción de los poli fenoles y microorganismos.

\section{CONCLUSIONES}

Con el uso de Microorganismos eficientes se logra estabilizar más rápido los menores tiempos de fermentación; En lo que respecta a $\mathrm{pH}$ y temperatura de la masa con relación al testigo, los tratamientos 1 y 3 presentaron las mayores diferencias. El uso de aditivos orgánicos como miel de panela, EM y té de limoncillo en el proceso de fermentación mejora notoriamente los atributos de la bebida, logrando estandarizar y mejorar la calidad de la taza. Se resalta el promedio de factor de rendimiento para todos los tratamientos que fue de 84,4 destacando que se ha logrado mantener la calidad no solo en el aspecto sensorial, al contrario, se mantiene constante la calidad física del grano. Los resultados presentan alternativas viables y de fácil aplicación para que caficultores (pequeños, medianos o grandes), puedan implementarlas y esperar mejor calidad del producto y así poder ingresar a los mercados de cafés especiales.

\section{BIBLIOGRAFÍA}

Bonilla Morales, M., \& Caetano, C. (2013). Inventario y valoración de la flora utilizada por la vereda Santa Teresa, Palmira (Valle del Cauca). Revista de Investigación Agraria y Ambiental, 4(1), 89-99. doi:https://doi.org/10.22490/21456453.985

Centro Nacional de Investigaciones de Café, CENICAFÉ. 1996. Extracto del libro: Beneficio ecológico del café: una opción rentable, Chinchiná, octubre 16-18. 
Coffee Association of America SCAA. 2015. Protocols Cupping Specialty Coffee. Published by the Specialty. Recuperado de https://www.scaa.org/?page=bios\&bio=ellie

Corredor Camargo, E., Fonseca Carreño, J., \& Páez Barón, E. (2012). Los servicios ecosistémicos de regulación: tendencias e impacto en el bienestar humano. Revista de Investigación Agraria y Ambiental, 3(1), 77-83. doi:https://doi.org/10.22490/21456453.936

Duarte, L. A., Arana-Gutiérrez, A. D. (2016). Medio ambiente y naturaleza al servicio del capital corporativo transnacional. Revista Criterio Libre Jurídico. 13(1), 85-103 Recuperado de: http://revistasojs.unilibrecali.edu.co/index.php/rclj/article/download/546/86 $\underline{5}$

Gamboa García, D. (2015). Valoración de impactos ecológicos por minería de oro en río Guabas, Valle del Cauca, Colombia. Revista de Investigación Agraria y Ambiental, 6(2), 243 - 254. doi:https://doi.org/10.22490/21456453.1420

Giraldo Díaz, R., \& Valencia T., F. (2010). Evaluación de la sustentabilidad ambiental de tres sistemas de producción agropecuarios, en el corregimiento Bolo San Isidro, Palmira (Valle del Cauca). Revista de Investigación Agraria y Ambiental, 1(2), 717. doi:https://doi.org/10.22490/21456453.900

Martín Gordo, D. (2018). Los Compuestos Fenólicos, Un Acercamiento A Su Biosíntesis, Síntesis Y Actividad Biológica. Revista de Investigación Agraria y Ambiental, 9(1), 81 - 104. doi:https://doi.org/10.22490/21456453.1968

Matos de Oliveira, A. (2014). Crítica ecológica al concepto de Desarrollo y nuevas alternativas desde América Latina. Revista de Investigación Agraria y Ambiental, 5(2), 41 - 53. doi:https://doi.org/10.22490/21456453.1325

Mendoza Velásquez, S., Cano Muñoz, J., \& Rojas Sánchez, F. (2015). Acción comunitaria frente al fenómeno del cambio climático, en el páramo de la región del Guavio, Cundinamarca, Colombia. Revista 
de Investigación Agraria y Ambiental, 6(1), 265 - 279.

doi:https://doi.org/10.22490/21456453.1286

Puerta, Q, Gloria, I. 2012. Factores, procesos y controles en la Fermentación del Café. [En Línea]. 12pp Disponible En http://www.cenicafe.org/es/publications/avt0422.pdf

Puerta Q, Gloria, I. 2015. Cenicafe-Aseguramiento De La Calidad Del Café Y De Sabores Especiales Mediante Procesos Controlados. [En Línea]. 33pp Disponible En Http://Expoespeciales.Com/Pdf/Memorias/Expoespeciales-2015Memorias-Calidad-Cafe-Procesos-Controlados.Pdf

Specialty Coffee Association SCA. 2004. Formulario de catación Valoración de la calidad del café. Specialty Coffee association. Disponible en https://sca.coffee/

Vera Romero, R., \& Vera Romero, C. (2016). Fortalecimiento de las competencias administrativas en los extensionistas del Comité de Cafeteros de Colombia. Revista de Investigación Agraria y Ambiental, 7(1). doi:https://doi.org/10.22490/21456453.1617

Vinasco Guzmán, M. (2017). Marco teórico para la construcción de una propuesta de turismo rural comunitario. Revista de Investigación Agraria y Ambiental, 8(1), 95 - 106. doi:https://doi.org/10.22490/21456453.1841

Zapata Galvis, J., \& Llano Franco, J. (2014). Perspectiva interdisciplinaria del ordenamiento alimentario y derecho del consumidor en Argentina. Revista de Investigación Agraria y Ambiental, 5(2), 99 114. doi:https://doi.org/10.22490/21456453.1329

\section{Agradecimientos}

Se hace un especial reconocimiento a los productores de café del municipio de "El Tambo" departamento del Cauca. También a la Federación Campesina del Cauca y la Federación Nacional de Cafeteros. 
Working papers - ECAPMA 